\title{
Profile of patients hospitalized with odontogenic infections in a public hospital in Belo Horizonte, Brazil
}

\author{
Augusto César Sette-Dias ${ }^{1}$, Amália Jorge Tanos Maldonado ${ }^{2}$, Evandro Guimarães de Aguiar ${ }^{3}$, Maria Auxi- \\ liadora Roque de Carvalho ${ }^{4}$, Paula Prazeres Magalhães ${ }^{4}$, Luiz de Macêdo Farias ${ }^{4}$, Evandro Neves Abdo ${ }^{3}$ \\ ${ }^{1}$ Student of Stomatology, Faculdade de Odontologia, Universidade Federal de Minas Gerais, Belo Horizonte, Brazil. \\ ${ }^{2}$ Undergraduate Student, Faculdade de Odontologia, Universidade Federal de Minas Gerais, Belo Horizonte, Brazil. \\ ${ }^{3}$ Professor, Faculdade de Odontologia, Universidade Federal de Minas Gerais, Belo Horizonte, Brazil. \\ ${ }^{4}$ Professor, Instituto de Ciências Biológicas, Universidade Federal de Minas Gerais, Belo Horizonte, Brazil.
}

Correspondence:

Faculdade de Odontologia,

Universidade Federal de Minas Gerais.

Av. Antônio Carlos 6627,

CEP: 31270-901, Belo Horizonte, Brazil.

E-mail address: gutodonto@yahoo.com.br

Sette-Dias AC, Maldonado AJ, Aguiar EG, Carvalho MAR, Magalhães PP, Farias LM, Abdo EN. Profile of patients hospitalized with odontogenic infections in a public hospital in Belo Horizonte, Brazil. J Clin Exp Dent. 2012;4(5):e271-4.

http://www.medicinaoral.com/odo/volumenes/v4i5/jcedv4i5p271.pdf

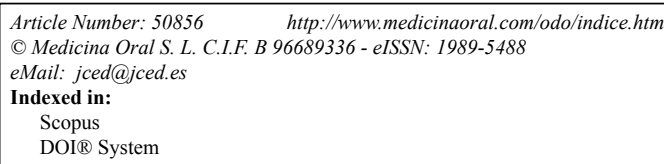

\begin{abstract}
Objectives: We aimed to evaluate the profile of hospitalized patients presenting with odontogenic infections requiring intensive care and to identify predictive factors of worsening of the disease.

Study Design: In this retrospective study, 119 consecutive medical records were assessed for data regarding odontogenic infections. The variables examined were age, gender, etiology, time from onset of infection to hospital admission, hospital stay, complications during hospitalization, and anatomical sites affected.

Results: Most patients were female (64.7\%) and the mean age of our study group was 28.3 years. Average length of hospital stay was $7.3 \pm 6.3$ days and the mean time from onset of infection to hospitalization was 6.9 days. Lower teeth corresponded to the initially affected site in the great majority $(72.3 \%)$ of the cases and the mandibular third molar was the most commonly first infected tooth (31.9\%). Post-surgical infection was involved in $21.8 \%$ of the cases. Systemic conditions were reported for $18.5 \%$ of the patients, mainly hypertension, but they were not determinant for admission. The main reasons for hospitalization were dyslalia, dysphagia, and dyspnea, either as single or associated signs $(96.6 \%)$. Antimicrobial therapy was administered alone or combined with surgical drainage to $64(53.8 \%)$ and $53(44.5 \%)$ patients, respectively.

Conclusions: Overall data generated by this investigation on the profile of severe odontogenic infection patients in our region are similar to those reported by other researchers. Conversely we found a higher prevalence of the disease among women in disagreement with previously published results. Such a kind of study may improve our knowledge relative to the disease and also reveal the regional scenario regarding severe odontogenic infections. Consequently it may contribute to the designing of strategies that may lead to a more efficient oral health care system what ultimately would culminate with the prevention of more severe outcomes from the disease.
\end{abstract}

Key word: Odontogenic infection, antimicrobial therapy, epidemiology. 


\section{Introduction}

Dental infections are defined as infectious processes that affect teeth themselves or their supporting structures. Most infections that arise in the oral cavity should be considered as primary odontogenic infections, the most common of them being related to dental caries, gingivitis, and periodontitis (1). These polymicrobial infections are associated with a variety of aerobic and anaerobic microorganisms indigenous to the oral cavity (2).

Usually, these infections present as well-defined processes and are limited to adjacent tissues. However in some cases they become both complex and disseminated. The processes spread most often along anatomical planes, always seeking the path of least resistance (3).

Due to possible complications in the course of the disease, emergent hospitalization might be necessary. Treatment in these cases consists of administration of intravenous antibiotics, drainage, debridement, and airway maintenance among other forms of supportive care $(1,4,5)$.

This study aimed to evaluate the profile of patients presenting with odontogenic infections requiring intensive care and to identify predictive factors of worsening of the disease.

\section{Patient and Methods}

The study was approved by the Ethics Committees of the Hospital Municipal Odilon Behrens (HMOB) and the Universidade Federal de Minas Gerais (ETIC 374/08). A total of 119 of 150 consecutive patients presenting with odontogenic infections who searched for assistance at HMOB, Belo Horizonte, Brazil, from February 2008 to January 2010 were included in this retrospective study. HMOB is a public referral hospital that attends to about 13,000 patients monthly. The Hospital provides emergency dental care and maxillofacial surgery with monthly averages of 1,800 and 520 patients, respectively.

The variables examined were age, gender, etiology, time from infection onset to hospitalization, hospital stay, complications during hospitalization, and anatomical sites initially affected.

Statistical analysis was performed by employing Pearson's chi-square test using SPSS, version 17.0

\section{Results}

Data regarding gender and age of patients and length of hospital stay are depicted on Table 1. Most patients were female $(77 / 64.7 \%)$ and the mean age of our study group

\begin{tabular}{lllll}
\hline \multirow{2}{*}{ Gender } & \multirow{2}{*}{ Number(\%) } & \multicolumn{3}{c}{ Age } \\
\cline { 3 - 5 } & & Mean & SD $^{\mathbf{a}}$ & Range \\
\hline Male & $42(35.3)$ & 28.43 & 14.874 & $6-67$ \\
Female & $77(64.7)$ & 28.21 & 14.680 & $4-79$ \\
\hline
\end{tabular}

a, standard deviation.

Table 1. Distribution of 119 patients with odontogenic infections who searched for assistance in a public hospital of Belo Horizonte, Brazil based on gender and age. was 28.3 years. Length of hospital stay ranged from 2 to 57 days, mean $7.3 \pm 6.3$ days (data obtained for 118 patients) and the mean time from onset of infection to hospital admission was 6.9 days.

Concerning initially affected site lower teeth were involved in $86(72.3 \%)$ cases, upper teeth in two $(1.7 \%)$ cases, deciduous teeth were responsible for nine $(7.6 \%)$ cases, and for $22(18.5 \%)$ patients tooth were infection originated could not be determined. The mandibular third molar was the most commonly initially infected tooth ( 38 cases, $31.9 \% ; p=0.002$ ). Also an intimate relationship between lower molars, mainly third molars, and the involvement of the submandibular space was detected $(\mathrm{p}=0.036)$.

The great majority of cases $(93 / 78.2 \% ; p=0.003)$ was not related to surgical procedures. Only $26(21.8 \%)$ cases were characterized as post-surgical infection. Within this group removal of third molars was significantly associated with the development of odontogenic infections $(65.4 \% ; \mathrm{p}=0.003)$ (Table 2).

Systemic conditions were reported for $22(18.5 \%)$ pa-

\begin{tabular}{|c|c|c|c|}
\hline Tooth & $\begin{array}{l}\text { Postope- } \\
\text { rative in- } \\
\text { fection }\end{array}$ & Others $^{\mathrm{a}}$ & Total \\
\hline Mandibular first molar & $1(3.8)^{b}$ & $23(24.7)$ & $24(20.2)$ \\
\hline $\begin{array}{l}\text { Mandibular second } \\
\text { molar }\end{array}$ & $1(3.8)$ & $14(15.1)$ & $15(12.6)$ \\
\hline Mandibular third molar & $17^{\mathrm{c}}(65.4)$ & $21(22.6)$ & $38^{\mathrm{d}}(31.9)$ \\
\hline Mandibular premolar & $3(11.5)$ & $4(4.3)$ & $7(5.9 \%)$ \\
\hline $\begin{array}{l}\text { Mandibular canine and } \\
\text { incisor }\end{array}$ & $1(3.8)$ & $1(1.1)$ & $2(1.7 \%)$ \\
\hline Maxillar molar & $0(0.0)$ & $1(1.1)$ & $1(0.8 \%)$ \\
\hline Maxillar premolar & $0(0.0)$ & $1(1.1)$ & $1(0.8 \%)$ \\
\hline Deciduous teeth & $1(3.8)$ & $8(8.6)$ & $9(7.6 \%)$ \\
\hline Unidentified & $2(7.7)$ & $20(21.5 \%)$ & $22(18.5 \%)$ \\
\hline Total & $26(21.8)$ & $93^{\mathrm{e}}(78.2)$ & 119 \\
\hline
\end{tabular}

${ }^{a}$, others include pericoronaritis and endodontic and periodontal infections; ${ }^{b}$, number $(\%)$ of patients; ${ }^{c}, p=0.003 ;{ }^{d}, p=0.002 ;{ }^{e}, p=$ 0.003 (Person's chi-square test).

Table 2. Site of origin of odontogenic infections among 119 patients who searched for assistance in a public hospital of Belo Horizonte, Brazil.

tients. Among them, hypertension was observed in nine $(7.6 \%)$, diabetes mellitus in six $(5.0 \%)$, respiratory disease in two (1.7\%), and endocrinopathy and AIDS in one $(0.8 \%)$ patient each.

Regarding the reason for hospitalization dyslalia, dysphagia, and dyspnea, either as single or associated signs, were observed for 115 (96.6\%) patients (Fig. 1). The cause for hospitalization was not available for three $(2.5 \%)$ cases. Other signs or symptoms reported at the time of admission included edema (1/0.8\%); trismus and edema (15/12.6\%); trismus, pain, and edema (33/27.7\%); and trismus, pain, swelling, and fever (68/57.1\%). 


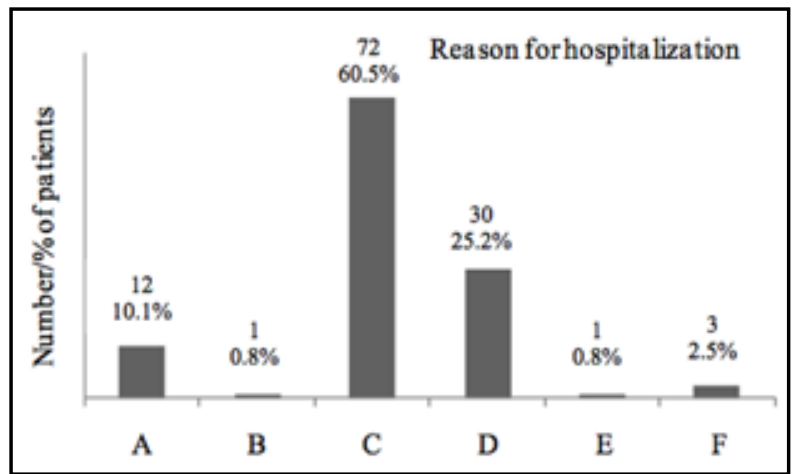

Fig. 1. Reasons for hospitalization of 119 patients with odontogenic infections who searched for assistance in a public hospital of Belo Horizonte, Brazil. A, dysphagia; B, dyspnea; $C$, dyslalia and dysphagia; D, dyslalia, dysphagia, and dyspnea; E, tachycardia; F, data not available.

Antimicrobial therapy was administered alone or combined with surgical drainage to $64(53.8 \%)$ and 53 (44.5\%) patients, respectively. For two (1.7\%) cases data regarding treatment was not available. Tracheotomy was required by seven $(5.9 \%)$ patients and two $(1.7 \%)$ patients died.

\section{Discussion}

This study generated relevant data regarding severe odontogenic infection, a still poorly known condition. We report a significantly higher prevalence of the disease among women (64.7\%). This result diverges from those published by other researches who describe no gender preference or a predominance of affected males $(6,7,8,9)$. We have no ready explanation for the finding and further investigations are still needed to clarify this discrepancy.

When comparing the average ages of men and women included in our study group no statistical difference was observed. Higher mean ages of odontogenic infection patients ranging from about 30 to 50 years have already been reported $(10,11,12)$.

The average hospital stay was 7.3 days, which was in accordance with literature data that report hospitalization periods ranging from 5.1 to 14.8 days $(7,13,14)$. The mean interval between infection and hospitalization (6.9 days) was similar to the time that usually a small odontogenic abscess lasts, between 5 to 7 days (15). Length of hospital stay was not significantly correlated with evolution time.

Corroborating findings reported by other authors $(8,13)$ we found that most of infections originated from molar teeth especially third molars regardless of association with surgical procedures. When only patients for whom the site of origin of the infection could be determined were considered 39.2 of the cases were associated with third molars. Postoperative events accounted for around $21.8 \%$ of cases consistently with findings published by Boffano and coworkers (4). The association between re- moval of third molars and development of odontogenic infections are also in agreement with a report by Kunkel and coworkers (16) who observed that infection is the most common severe complication derived from third molars extraction.

The close relationship between lower molars, mainly third molars, and dissemination of the infection to the submandibular space corroborates previously reported observations. The involvement of the mouth floor with respect to submandibular, sublingual or submental spaces is considered to contribute to disease severity, due to upper airway obstruction and to higher risk of infection spread to cervical fascial space and mediastine (3). In fact, it was observed that dyslalia, dysphagia, and/or dyspnea resulting from the involvement of these anatomical spaces were registered for $96.6 \%$ of the patients as the reason for hospitalization.

When evaluating the relatively low prevalence of systemic diseases ( $18.5 \%$ of the overall sample), with higher incidences of hypertension and diabetes mellitus, one must consider the average age of patients of our study group. Indeed, it has already been described (as expected) an association between increased prevalence of underlying diseases and higher mean age of odontogenic infection patients (14). It is plausible to assume that systemic changes did not decisively influenced hospitalization rates in this study.

The most significant complications observed were those that had led to the need for tracheotomy, which have been performed in seven (5.9\%) patients. This procedure is considered essential in cases of upper airway obstruction due to the involvement of the spaces of mouth floor and neck. The mortality rate was $1.7 \%$. These two patients presented with comorbidities, one suffering from a degenerative disease and the other from AIDS. These findings are in agreement with literature data. It has already been reported a predisposition for the occurrence of dental infections in patients with severe comorbidities $(17,18)$.

Regarding treatment, the protocol established by HMOB consisted of antibiotics administration (clindamycin and gentamicin) associated, if necessary, with surgical drainage. In fact it is taken as a general rule that the first implemented procedure for treating odontogenic infection patients should be the establishment of broad-spectrum antibioticotherapy. If there is no clinical improvement in 24 or 48 hours, drainage surgery is indicated (19).

Our study group was composed by patients from the metropolitan area of Belo Horizonte that has 34 municipalities. The population estimated at $4,883,970$ inhabitants is taken as highly diverse with respect to several parameters including socioeconomic traits (20). The lack of occupational data in the medical records evaluated impaired the evaluation of socioeconomic status of our study group what should be considered as a limitation 
of the study. However as already mentioned HMOB is a public referral hospital that provides emergency care for patients of the Sistema Único de Saúde (SUS - Brazilian public health system). According to Rocha and Simões (21), there are few beds in private hospitals destined to patients coming from SUS who are mainly unskilled and semi-skilled manual workers. Therefore, although the records did not include socioeconomic information it is reasonable to assume that most of our patients would be included in a low socioeconomic stratum.

Data generated by this investigation showed that characteristics of severe odontogenic infections in our region are comparable to those reported in the literature considering teeth or dental position implicated as the initial focus of infection, hospitalization, signs and symptoms of the disease, and treatment. On the other hand although mean age of affected patients was similar to that observed by other authors we found a higher prevalence of the disease among women suggesting peculiarities of the Brazilian population that could be reflected in the pathogenesis of the disease. It should be highlighted that odontogenic infections are polymicrobial diseases associated with a diverse and complex microbiota indigenous to the oral ecosystem. This stresses the need for additional studies on the prevalence and drug susceptibility profiles of the major microbial groups implicated in the ethiopathogenesis of the disease in order to generate data that reflect the regional scenario. In fact this is the only way to improve diagnosis and treatment and help to minimize antimicrobial resistance rates. It is crucial the improvement of public oral health care and it is also fundamental that dentists recognize the signs of severe odontogenic infection for a proper and timely care of patients in order to prevent serious outcomes from the disease.

\section{Acknowledgments}

The authors would like to thank Hospital Municipal Odilon Behrens for authorizing the release of medical records.

\section{References}

1. de Vicente Rodríguez JC. Maxillofacial cellulitis. Med Oral Patol Oral Cir Bucal. 2004;9:126-33.

2. Robertson D, Smith AJ. The microbiology of the acute dental abscess. J Med Microbiol. 2009;58:155-62.

3. Pynn BR, Sands T, Pharoah MJ. Odontogenic infections: Part one. Anatomy and radiology. Oral Health. 1995;85:7-10,13-4,17-8 passim.

4. Boffano P, Roccia F, Pittoni D, Di Dio D, Forni P, Gallesio C. Management of 112 hospitalized patients with spreading odontogenic infections: correlation with DMFT and oral health impact profile 14 indexes. Oral Surg Oral Med Oral Pathol Oral Radiol Endod. 2012;113:2007-13.

5. Uluibau IC, Jaunay T, Goss, AN. Severe odontogenic infections. Austral Dent J. 2005;50:74-81.

6. Flynn TR, Shanti RM, Levi MH, Adamo AK, Kraut RA, Trieger N. Severe odontogenic infections, part 1: prospective report. J Oral
Maxillofac Surg. 2006;64:1093-103.

7. Lee JK, Kim HD, Lim SC Predisposing factors of complicated deep neck infection: an analysis of 158 cases. Yonsei Med J. 2007;48:55-62

8. Zaleckas L, Rasteniene R, Rimkuviene J, Seselgyte R. Retrospective analysis of cellulitis of the floor of the mouth. Stomatologija. 2010;12:23-7.

9. Rega AJ, Aziz SR, Ziccardi VB. Microbiology and antibiotic sensitivities of head and neck space infections of odontogenic origin. J Oral Maxillofac Surg. 2006;64:1377-80.

10. Peters ES, Fong B, Wormuth DW, Sonis ST. Risk factors affecting hospital length of stay in patients with odontogenic maxillofacial infections. J Oral Maxillofac Surg. 1996;54:1386-91.

11. Zhang C, Tang Y, Zheng M, Yang J, Zhu G, Zhou H. Maxillofacial space infection experience in West China: a retrospective study of 212 cases. Int J Infect Dis. 2010;14:414-7.

12. Sato FR, Hajala FA, Freire Filho FW, Moreira RW, De Moraes M. Eight-year retrospective study of odontogenic origin infections in a postgraduation program on oral and maxillofacial surgery. J Oral Maxillofac Surg. 2009;67:1092-7.

13. Ylijoki S, Suuronen R, Jousimies-Somer H, Meurman JH, Lindqvist C. Differences between patients with or without the need for intensive care due to severe odontogenic infections. J Oral Maxillofac Surg. 2001;59:867-72.

14. Seppänen L, Rautemaa R, Lindqvist C, Lauhio A. Changing clinical features of odontogenic maxillofacial infections. Clin Oral Investig. 2010;14:459-65.

15. Brennan MT, Runyon MS, Batts JJ, Fox PC, Kent ML, Cox TL. Odontogenic signs and symptoms as predictors of odontogenic infection: a clinical trial. J Am Dent Assoc. 2006;137:62-6.

16. Kunkel M, Kleis W, Morbach T, Wagner W. Severe third molar complications including death-lessons from 100 cases requiring hospitalization. J Oral Maxillofac Surg. 2007;65:1700-6.

17. Huang TT, Tseng FY, Liu TC, Hsu CJ, Chen YS. Deep neck infection in diabetic patients: comparison of clinical picture and outcomes with nondiabetic patients. Otolaryngol Head Neck Surg. 2005;132:943-7.

18. Carey JW, Dodson TB. Hospital course of HIV-positive patients with odontogenic infections. Oral Surg Oral Med Oral Pathol Oral Radiol Endod. 2001;91:23-7.

19. Boscolo-Rizzo P, Da-Mosto MC. Submandibular space infection: a potentially lethal infection. Int J Infect Dis. 2009;13:327-33.

20. Instituto Brasileiro de Geografia e Estatística; Censo Demográfico 2010 (homepage). Brasilia, DF. Ministério do Planejamento, Orçamento e Gestão. [cited 2011 Aug 30] Available from: URL:www. sidra.ibge.gov.br/bda/tabela/protab.asp? $\mathrm{c}=3107 \& \mathrm{z}=\mathrm{t} \& \mathrm{o}=4 \& \mathrm{I}=\mathrm{P}$

21. Rocha JS, Simões BJ. Study of public and private hospital care on a population basis, 1986-1996. Rev Saúde Pública. 1999;33:44-54. 